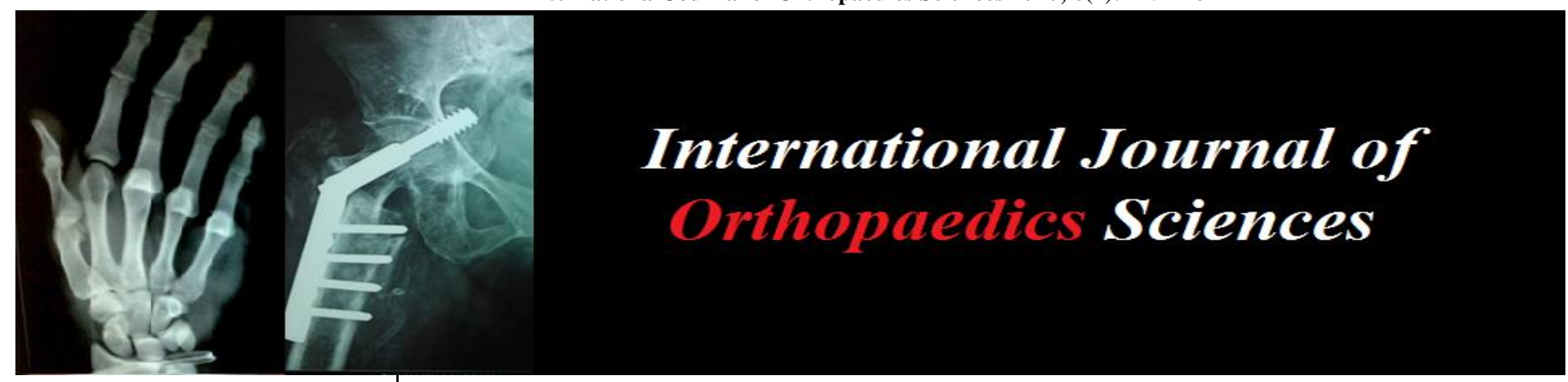

E-ISSN: 2395-1958

P-ISSN: 2706-6630

IJOS 2020; 6(2): 715-718

(C) 2020 IJOS

www.orthopaper.com

Received: 08-02-2020

Accepted: 10-03-2020

Dr. Saurabh Dwivedi

(Resident), Department of

Orthopaedics, SN Medical

College, Agra, Uttar Pradesh,

India

Dr. Chandra Prakash Pal

(Head of Department),

Department of Orthopaedics, SN

Medical College, Agra, Uttar

Pradesh, India

Dr. Kamal Safdar

(Resident), Department of Orthopaedics, SN Medical

College, Agra, Uttar Pradesh, India
Corresponding Author: Dr. Saurabh Dwivedi (Resident), Department of Orthopaedics, SN Medical College, Agra, Uttar Pradesh, India

\section{Comparison of outcome of fracture distal end radius treated by external fixator versus volar plating}

\author{
Dr. Saurabh Dwivedi, Dr. Chandra Prakash Pal and Dr. Kamal Safdar
}

DOI: https://doi.org/10.22271/ortho.2020.v6.i21.2126

\begin{abstract}
Introduction: Distal Radius Fractures occur with a high frequency and continue to be most common skeletal injuries treated by orthopedic surgeon and these injuries accounting for approximately one sixth of all fractures seen in emergency. As fractures occur through cancellous bone union is not a problem. All the treatment is aimed towards anatomical reduction to prevent malunion and achieve good functional results. This study was aimed to compare the relative efficacy of external fixation versus plating with regard to functional and radiological outcome.

Material and method: A prospective comparative study was conducted, studying 50 cases of unstable distal end radius fractures who were fitting in the inclusion criteria. It followed AO classification to classify cases and then compare the various outcomes to get the better modality of treatment with an average follow-up of 11 months. The two groups were compared for clinical and functional outcomes measured by MAYO score. Radiographic measurements were also evaluated between groups.

Results: Final ranges of motion and grip strengths were better in ORIF group as compared to External Fixation. The mean MAYO score of the locked volar plate group was 85 compared to 78 for the external fixation group. Radiographically, volar tilt and radial length were significantly better in the patients treated with ORIF. No complications occurred in the locked volar plate group whereas three patients had pin tract infections and two had prolonged finger stiffness in the external fixation group.

Conclusion: We concluded that fracture fixation with volar plate and screw system in the management of distal radius articular fractures, is a superior method to maintain the reduction till union and prevent the collapse of the fracture fragments, even in grossly comminuted, unstable and osteoporotic bones; as compared with external fixator. Whereas grip strength, range of motion, MAYO scores, frequency of rehabilitation, and some radiographic parameters were superior in patients treated with ORIF.
\end{abstract}

Keywords: Comparison of outcome fracture distal, external fixator versus volar plating

\section{Introduction}

Distal Radius Fractures occur with a high frequency and continue to be most common skeletal injuries treated by orthopedic surgeon and these injuries accounting for approximately one sixth of all fractures seen in emergency ${ }^{[1]}$. There is bimodal distribution in children and elderly ${ }^{[2]}$. Incidence is higher in female because of low bone mineral density and a tendency to fall consequently. In modern world with increase in speed and number of fast moving vehicles there is great increase in number and severity of fractures. Road traffic accident is major cause of these fractures in adult ${ }^{[3]}$. As the wrist joint is associated with both fine work and weight lifting hence restoration of radial length, radial tilt and congruity of articular surfaces is important for good functional results ${ }^{[4,5,6]}$. As fractures occur through cancellous bone union is not a problem. All the treatment is aimed towards anatomical reduction to prevent malunion and achieve good functional results. Intra-articular fractures are inherently unstable, difficult to reduce anatomically and immobilize in closed pop cast and are associated with high rates of complications ${ }^{[7]}$. External fixation is generally accepted as superior to plaster immobilization in young patients with intra-articular comminuted displaced distal radius fractures ${ }^{[8,9,10]}$.

Open reduction and internal fixation with dorsal or volar plates can yield successful results [11, 12, 13]. The advantages for this plating system include the ability to hold the intra-articular fragments securely without crossing the wrist. This allows early active wrist motion with maintaining distal articular alignment. However, plate fixation is associated with complications that include tenosynovitis, tendon rupture, complex regional pain syndrome, 
carpal tunnel syndrome and intra-articular penetration of screws $[14,15]$. Tendon complications are higher with dorsal plating ${ }^{[16]}$. External Fixation acts by maintaining length whilst neutralizing compressive, torsional and bending forces across the fracture site ${ }^{[17]}$. External fixation has enjoyed success, but also been associated with complications such as stiffness of the wrist and fingers, loss of reduction, problems with the radial sensory nerve and pin-tract infection ${ }^{[18,19]}$.

In this prospective, comparative study the AO classification of distal radius fracture will be use. The purpose of this study to compare the relative efficacy of external fixation versus plating with regard to functional and radiological outcome.

\section{Materials and methods}

This prospective study was conducted in department of orthopaedics SNMC and hospital Agra to compare functional as well as radiological outcome of external fixation and volar plating for treatment of unstable distal radius fractures. This study was performed between November 2017 to May 2019 in those patients attending emergency and OPD orthopedics and fulfilling inclusion criteria would be included. The inclusion criteria of study were those patients age between 2070 years and treated less than 2 weeks after injury with AO type $\mathrm{B}$ and $\mathrm{C}$ distal radius fractures. Those excluded patients with fractures exposed to or associated with tendon or neurovascular lesions, patients with severe comorbidities, patients with cognitive deficit which do not understand elements of functional evaluation and consent form refusal patients.

The patients were classified into two groups external fixation and volar plating group. Both surgical procedures performed by a single author at a single institute using standard protocols under general or regional anaesthesia. External fixation technique used $2.5 \mathrm{~mm}$ schanz pins in second metacarpal and $3.5 \mathrm{~mm}$ pins in the radius proximal to fracture. The metacarpal and radius pins were interconnected with connecting rod and link joints after application of frame reduction done and checked in $\mathrm{C}$-arm in anteroposterior and lateral view. Reduction was achieved by manual traction and closed reduction method in all cases. Now sterile pin tract dressing done. The external fixator was removed in all patients after 6-8 weeks by confirming radiological union.

In volar locked plating technique patient laid supine on operating table and affected extremity extended over a radiolucent table. The procedure was performed under general anaesthesia or regional block. All patients were given IV antibiotic for preoperative prophylaxis. Tourniquet and cautery were used for hemostasis. Now a longitudinal incision of 6-8 $\mathrm{cm}$ was given across the volar aspect of distal radius. Incise and retract the superficial and deep fascia and plane was created between brachioradialis muscle laterally and flexor pollicis longus, flexor carpi radialis, radial artery and median nerve medially. This exposes the pronator quadratus muscle and volar radial surface. Now incise radial and distal border of pronator quadratus elevating the muscle off the volar radius. Reduction maneuver was done under direct vision as well as with the help of fluoroscopy. The plate was slide under muscle and applied over distal fragment. The plate placement help to reduce fracture fragments and restore contour of bone under fluoroscopy and direct vision.

Once the proper reduction was achieved the distal and proximal locking screws were put into place. Screw placement and reduction was checked under C-arm. Proper wash given. Pronator quadratus was placed back to its place and subcutaneous and skin closure was done. Dressing was done with maintaining all sterile precautions. A below elbow pop slab was applied for one week. Radiograph of the wrist joint were

taken after surgery. Patients of both groups were discharged two days after surgery after checking the suture line and pin tract dressing under proper antibiotic coverage and active finger movement were advised. The patients were recalled for suture removal and to see the reduction in fracture radio logically after two weeks.

\section{Post-operative management}

Immediate post operatively limb was elevated and sling applied. Patients were treated with intravenous antibiotics for 2 weeks and oral antibiotics for further 4 weeks. Suture removal was done on 12th day post-operatively. Physiotherapy in form of active finger movement were started. After removal of splint in 10 to 14 days following post operatively gentle range of motion started. Over next 2-4 weeks progressive advance of motion is performed. Depending on the clinical and radiographic status, activity is advanced to include strengthening at approximately 6 weeks. In case of external fixation pin tract dressing done at regular interval. Physiotherapy in form of active finger movement and gentle pronation and supination of approximately $45^{\circ}$ was started on each direction despite the distal radioulnar joint involvement. Fixator was removed 6-8 weeks after clinical and radiological healing of fracture as an outdoor procedure. Wrist mobilization was started after fixator removal. Patients were protected by below elbow pop slab for 2 weeks after removal of fixator. They were allowed to do light works after 3 months and heavy works allowed after 5 months postoperatively. Follow up appointment occurs at 2, 4 and 8 weeks and at 3,6- and 12-months post operatively. At each visit or follow up pain, range of motion and grip strength was noted.

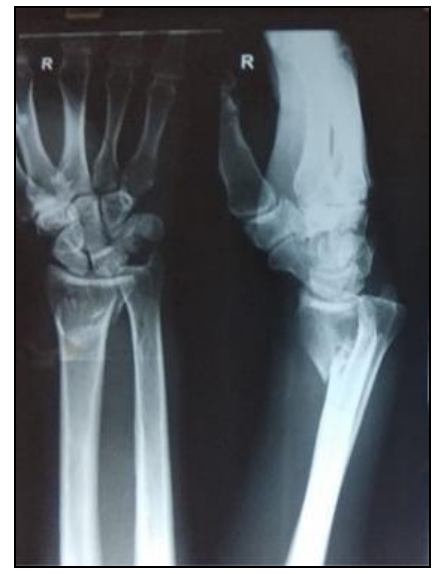

A

Preop

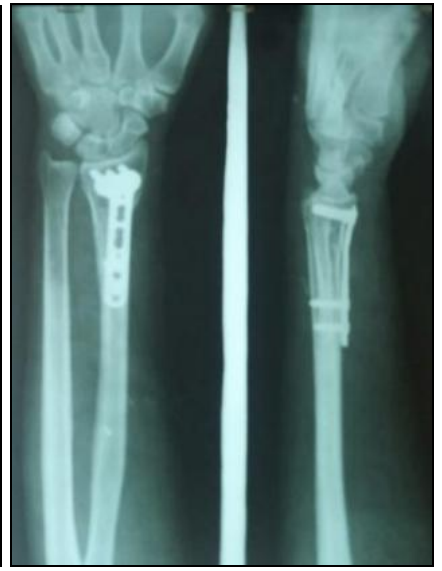

B

Immediate postop
Fig: A AP and lateral radiographs demonstrating a preoperative distal end radius fracture. Figure B Postoperative films after locked volar plate show a well-maintained reduction with stable fixation.

Table 1: Demographic data between groups.

\begin{tabular}{|c|c|c|}
\hline & Volar plate group & Ex-fix and pinning \\
\cline { 2 - 3 } & $\mathbf{( N = 2 5 )}$ & $\mathbf{( N = 2 5 )}$ \\
\hline Gender (M/F ratio) & $19: 6$ & $15: 10$ \\
\hline Average age (years) & $43(22-58)$ & $44(21-65)$ \\
\hline Average follow-up & $12(10-15)$ & $10(8-14)$ \\
\hline (months) & & \\
\hline
\end{tabular}




\section{Results}

The clinical outcomes are summarized for both groups in Tables 2. Final ranges of motion and grip strengths were better in volar plating group as compared to external fixator. Wrist flexion and extension measured $76^{\circ}$ and $70^{\circ}$ in the volar plating group versus $64^{\circ}$ and $60^{\circ}$ respectively in the external fixator group. Radial and ulnar deviation averaged 20 and 34 respectively in the plating group, and 18 and 24 , respectively, in the external fixator group. Pronation and supination in the plating group measured $78 / 74^{\circ}$ versus $62 / 64^{\circ}$ in the external fixation group. The grip strengths measured $26 \mathrm{~kg}$ (88\%contralateral) in the external fixation group and $29 \mathrm{~kg}$ (90\% contralateral) in the plating group. Pain scores were not significantly different between groups. The MAYO score of the locked volar plating group was 85 compared to 78 for the external fixation group $(\mathrm{P}=0.0261)$. This denotes that there is significant difference in the functional outcome of modality of fixation of distal radius intra articular fractures by volar plating and external fixation. Thus, from above $\mathrm{p}$-value which is $<0.05$ disproving the null hypothesis and proves that volar plating fixation gives better result in terms of radiological and functional outcome as compared to external fixation. Absence of pain at the fracture site to direct pressure defined as clinical healing. For radiographic analysis by Sarmiento's modification of Lindstorm's criteria, the radial inclination, radial length and volar tilt all showed statistically significant outcomes favoring the locked volar plate group. The volar tilt averaged $8^{\circ}$ (range 3-20) for the Volar plating group versus $7^{\circ}$ (range 3-for the external fixation group ( $\left.\mathrm{P}=0.041\right)$. Radial height and inclination were not significantly different between groups. In the plating group, the radial height measured 10 $\mathrm{mm}$ (range 7-13); whereas in the external fixation group it averaged $8 \mathrm{~mm}$ (range $6-12$ ). The radial inclination measured $15^{\circ}$ (range $\left.18-27\right)$ and $16^{\circ}(15-25)$ between the plating and external fixation cohorts, respectively. There was a significant difference in the number of hand therapy visits required between groups in favor of the plating patients. On average, the volar plate group required four therapy appointments versus an average of ten in the external fixation group $(\mathrm{P}=0.01)$. Complications occurred in the locked volar plate group as finger stiffness in one patient whereas two patients had a pin tract infection and three had prolonged finger stiffness in the external fixation group.

Table 2: Clinical outcome data at final

\begin{tabular}{|c|c|c|c|c|c|}
\hline Follow-up at one year. & \multicolumn{2}{|c|}{ Volar plate group $(\mathrm{N}=25)$} & \multicolumn{2}{|c|}{ Ex-fix/pinning group $(\mathrm{N}=25)$} & \multirow{2}{*}{$\begin{array}{c}\text { P value } \\
\text { NS }\end{array}$} \\
\hline Pain $(0-25)$ & 25 & & 20 & & \\
\hline Flexion $\left(^{\circ}\right)$ & 76 & $(60-85)$ & 64 & $(50-80)$ & NS \\
\hline Extension $\left(^{\circ}\right)$ & 70 & $(50-90)$ & 60 & $(40-80)$ & NS \\
\hline Radial deviation $\left(^{\circ}\right)$ & 20 & $(15-25)$ & 18 & $(10-25)$ & NS \\
\hline Ulnar deviation $\left({ }^{\circ}\right)$ & 34 & $(22-40)$ & 24 & $(12-35)$ & NS \\
\hline Pronation $\left({ }^{\circ}\right)$ & 78 & $(60-80)$ & 62 & $(50-80)$ & NS \\
\hline Supination $\left(^{\circ}\right)$ & 74 & $(58-78)$ & 64 & $(54-78)$ & NS \\
\hline Grip strength, kg & 29 & -90 & 26 & -88 & NS \\
\hline \multicolumn{6}{|l|}{ (\% contralateral $)$} \\
\hline Time to clinical healing(weeks) & $6(3-7)$ & & $6.5(4-7)$ & & NS \\
\hline MAYO score & $85(60-95)$ & & 78 & $(45-95)$ & 0.0261 \\
\hline Therapy sessions & $4(1-10)$ & & 10 & $(4-16)$ & 0.01 \\
\hline \multirow{3}{*}{ Complications } & \multirow{3}{*}{ Finger stiffness (1) } & & \multicolumn{2}{|c|}{ Pin tract infection } & \\
\hline & & & $(2)$ & & \\
\hline & & & \multicolumn{2}{|c|}{ finger stiffness (3) } & \\
\hline
\end{tabular}

\section{Discussion}

The rise of intra articular distal radius fractures and its various presentations of complexity in even younger individuals are predominantly due to high energy trauma especially road traffic accidents. In our study, around $68 \%$ of patients are due to RTA and presented with polytrauma at the emergency ward.

The average mean age of our study was 44 years comparable to the one by Anakwe and Jupiter who had an average age of 48 and 43 years respectively.

Our study had a male predominance with 34 of 50 cases. The higher incidence among the males could be attributed to a highly active work group with a higher involvement in high energy trauma and high velocity injuries of RTA.

In our study right side (dominant) was involved in 28 out of the 50 study cases. The relatively more predisposition could be attributed to a more- protective and early defense mechanism when fall on the right side or using right hand.

In our study RTA formed the reason of trauma in 34 of the 50 study cases. The reason for this nearly same incidence could be an older mean age of case study where a low-energy trauma is more frequent is causing a fracture on the outset of an osteoporotic bone.

All in our study belong to either type B or type C of distal radius fractures and graded the severity accordingly. 17 of
Our 50 cases had sustained a complete intraarticular (AO type C) fracture. That is Type $\mathrm{C}$ fracture accounted for $34 \%$ in our study

The fixed angled volar locking plates is the relatively choice of implant was used in our patients, with maximum number of screws in the metaphyseal region. Recent biomechanical and clinical studies which were undertaken for knowing the distal radius fixation revealed placement of locking screws in the metaphyseal bone with as close as $5 \mathrm{~mm}$ close to the distal subchondral bone without violating its articular surface.

It became evident that more screw placement in the distal metaphyseal acts as reefing technique.

Improved biomechanical understandings of the ligaments of the wrist led to the implementation of reefing technique, placement of plate more distally in volar aspect such that screws in the distal metaphyseal fragment will buttress the fragments well and prevent collapse of the articular comminution.

The latest concept among the various researches in distal radius fixation is the introduction of variable angle locking screw.

As compared to Jupiter et al, the mean range of radiological evaluation include volar tilt is 7 , which is same as in our study using external fixator, and by using volar plating is 10 , which was same as study of Anakwe et al. 
As compared to Orbay $\mathrm{J}$ et al, mean range of radial height was $10 \mathrm{~mm}$ compare to $9 \mathrm{~mm}$ in our study using volar locking plate and $8 \mathrm{~mm}$ using external fixator.

In comparison of functional outcome, the range of movements are nearly same as in study of Jupiter et al. and Orbay et al.

In our study we had $24 \%$ of external fixator and $44 \%$ of volar plating associated with excellent result, which was comparable to Anakwe et al. and John k reported 24 and $44 \%$ with excellent result in external fixation and volar plating group respectively based on Mayo wrist score.

The results of volar locking plate subgroup patients were comparable to study of Bradway et al. but a vast majority $76 \%$ had good to excellent functional score and satisfactory movements.

Complications were at least and are comparable with standard studies. We had 2 patients with prominent wires, 2 cases with pin tract infection and 3 with finger stiffness.

In our study, among 25 external fixator cases, 3 had unstable distal fragments of distal radius, which needed to be augmented with additional $\mathrm{K}$ wire fixation.

Primary internal fixation of the distal radius fixed with variable angle screws of volar locking plate facilitates early mobilization and hence earlier return to activities with good range of movements, especially rotations.

\section{Conclusion}

With the above discussion the fracture fixation with volar plate and screw system in the management of distal radius articular fractures is a superior method to maintain the reduction till union and prevent the collapse of the fragments, even in grossly comminuted, unstable and osteoporotic bone as compared with external fixator.

\section{References}

1. Colles A. On the fracture of the carpal extremity of the radius. Edinburgh Med Surg. 1814; 10:182-6

2. Andersen DJ, Blair WF, Steyers CM, Adams BD, elKhouri GY et al. Classification of distal radius fractures: an analysis of interobserver reliability and intraobserver reproducibility. J Hand Surg Am. 1996; 21(4):574-582.

3. Akelman E. Distal radius fractures: concepts and complications. Orthopedics. 1996; 19:601-8.

4. The evolution of distal radius fracture management: Rafael J Diaz Garica \& Kevin C Chung. Hand clin. 2012; 28(2):105-111.

5. Jupiter JB. Current concepts review-Fractures of the distal end of the radius. J Bone Joint Surg (Am). 1991; 73-A;461-469.

6. Trumble TE, Schmitt SR, Vedder NB. Factors affecting functional outcome of displaced intraarticular distal radius fractures. J Hand Surg. 1994; 19A:325-340.

7. Wagner WF JR, Tencer AF, Kiser P, Trumble TE. Effects on intra-articular distal radius depression on wrist joint contact characteristics. J Hand Surg Am. 1996; 21:554-560.

8. Knirk JL, Jupiter JB. Intra-Articular Fractures of the Distal End of the Radius in Young Adults. J Bone Joint Surg. 1986; 68-A:647-659.

9. Szabo RM. Extra articular fractures of the distal radius.Othop Clin North Am. 1993; 24(2):229-237.

10. Cooney WP, Linscheid RL, Dobyns JH. External Pin Fixation for Unstable Colles' Fractures. J Bone Joint Surg. 1979; 61-A:840-845.

11. Jenkins NH, Jones DG, Mintow CW et al. External fixation and recovery of function following fractures of the distal radius in young adults. Injury. 1998; 19:235238.

12. Rein S, Schikore H, Schnieders W, Amlong M, Zwapp $\mathrm{H}$. Results of dorsal or volar plate fixation of AO type C3 distal radius fractures: a retrospective study. J Hand Surg. 2007; 32A:954-961.

13. Kamath AF, Zurakowski D, Day CS. Low profile dorsal plating for dorsally angulated distal radius fractures: an outcome study. J Hand Surg. 2006; 31A:1061-1067.

14. Chung KC, Watt AJ, Kotsis SV, Margaliot Z, Haase SC, Kim HM. Treatment of unstable distal radius fractures with the volar locking plating system. J Bone Joint Surg Am. 2001; 88:2687-2694.

15. Botte MJ, Davis JL, Rose BA, Von Schroeder HP, Gellman A, Zinberg EA et al. Complications of smooth pin fixation of fractures and dislocations in the hand and wrist. Clin Orthop Relat Res. 1992; 276:194-201.

16. Arora R, Lutz M, Hennerbichler A, Krappinger D, Espen D, Gabl M. Complications following internal fixation of unstable distal radius fracture with a palmar lockingplate. J Orthop Trauma. 2007; 21:316-322.

17. Ruch DS, Papadonikolakis A. Volar versus dorsal plating in the management of intra-articular distal radius fractures. J Hand Surg Am. 2006; 31:9-16.

18. Behrens FF. General theory and principles of external fixation. Clin Orthop Relat Res. 1989; 241:15-23.

19. Sanders RA, Keppal FL, Waldrop J. External fixation of distal radius fractures: results and complications. J Hand Surg. 1991; 16A:385-391.

20. Ahlborg HG, Josefsson PO. Pin-tract complications in external fixation of fractures of the distal radius. Acta Orthop Scand. 1999; 70:116-118. 